\title{
Preparation and Evaluation of Jojoba Oil Methyl Esters as Biodiesel and as a Blend Component in Ultra-Low Sulfur Diesel Fuel
}

\author{
Shailesh N. Shah • Brajendra K. Sharma • \\ Bryan R. Moser • Sevim Z. Erhan
}

Published online: 15 October 2009

(C) Springer Science + Business Media, LLC. 2009

\begin{abstract}
The jojoba plant (Simmondsia chinensis L.) produces seeds that contain around 50 to $60 \mathrm{wt} \%$ of inedible long-chain wax esters that are suitable as a potential feedstock for biodiesel (BD) production. Jojoba oil methyl esters (JME) were prepared from acid-catalyzed pretreated jojoba oil in order to evaluate important fuel properties of jojoba-based $\mathrm{BD}$, including kinematic viscosity, cloud point (CP), pour point (PP), cold filter plugging point (CFPP), acid value (AV), oxidative stability, and lubricity. A comparison was made with soybean oil methyl esters (SME) and relevant BD fuel standards such as ASTM D6751 and EN 14214. JME was characterized using Fourier transform infrared spectroscopy and ${ }^{1} \mathrm{H}$ and ${ }^{13} \mathrm{C}$ nuclear magnetic resonance. The CP, PP, and CFPP of JME were $-13^{\circ} \mathrm{C},-16^{\circ} \mathrm{C}$, and $-14^{\circ} \mathrm{C}$, respectively, which were superior to SME. The kinematic viscosity $\left(40^{\circ} \mathrm{C}\right)$ of $\mathrm{JME}$
\end{abstract}

Disclaimer Product names are necessary to report factually on available data; however, the USDA neither guarantees nor warrants the standard of the product, and the use of the name by USDA implies no approval of the product to the exclusion of others that may also be suitable.

S. N. Shah $(\bowtie) \cdot$ B. K. Sharma $\cdot$ B. R. Moser

National Center for Agricultural Utilization Research, Agricultural

Research Service, United States Department of Agriculture,

1815 North University Street,

Peoria, IL 61604, USA

e-mail: Shailesh.Shah@ars.usda.gov

B. K. Sharma

Department of Chemical Engineering,

Pennsylvania State University,

University Park, PA 16802, USA

S. Z. Erhan

Eastern Regional Research Center, Agricultural Research Service, United States Department of Agriculture,

600 East Mermaid Lane,

Wyndmoor, PA 19038, USA was $6.67 \mathrm{~mm}^{2} / \mathrm{s}$, which was higher than observed for SME. Blends (B5 and B20) of JME in ultra-low sulfur diesel fuel (ULSD) were also evaluated for the aforementioned fuel properties and compared to an analogous set of blends of SME in ULSD and relevant petro diesel fuel standards such as ASTM D975 and D7467. JME blends in ULSD displayed improved low-temperature properties in comparison to neat ULSD and blends of SME in ULSD. In summary, jojoba oil has potential as an alternative, nonfood feedstock for BD production.

Keywords Biodiesel · Blends · Diesel · Jojoba oil · Simmondsia chinensis

$\begin{array}{ll}\text { Abbreviations } \\ \text { AOCS } & \text { American Oil Chemists' Society } \\ \text { APT } & \text { acid-catalyzed pretreatment } \\ \text { APT-JO } & \text { acid-catalyzed pretreated jojoba oil } \\ \text { ASTM } & \text { American Society for Testing and Materials } \\ \text { AV } & \text { acid value } \\ \text { BD } & \text { biodiesel } \\ \text { CP } & \text { cloud point } \\ \text { CFPP } & \text { cold filter plugging point } \\ \text { FFA } & \text { free fatty acid } \\ \text { FAME } & \text { fatty acid methyl ester } \\ \text { FID } & \text { flame ionization detector } \\ \text { IP } & \text { induction period } \\ \text { IV } & \text { iodine value } \\ \text { JA } & \text { jojobyl alcohol } \\ \text { JME } & \text { jojoba oil methyl esters } \\ \text { JO } & \text { jojoba oil } \\ \text { OT } & \text { oxidation onset temperature } \\ \text { PDSC } & \text { pressurized differential scanning calorimetry } \\ \text { PP } & \text { pour point } \\ \text { RBD } & \text { refined, bleached, and deodorized }\end{array}$




$\begin{array}{ll}\text { SO } & \text { soybean oil } \\ \text { SME } & \text { soybean oil methyl esters } \\ \text { SMT } & \text { signal maximum temperature } \\ \text { TAG } & \text { triacylglycerols } \\ \text { ULSD } & \text { ultra-low sulfur diesel fuel }\end{array}$

\section{Introduction}

Simmondsia chinensis, commonly known as jojoba, is a perennial shrub belonging to the Simmondsiaceae family that is native to the Mojave and Sonoran deserts of Mexico, California, and Arizona. Jojoba is unique in that the lipid content of the seeds, which is between 45 and $55 \mathrm{wt} \%$, is in the form of long-chain esters of fatty acids (FA) and alcohols (wax esters) as opposed to triacylglycerols (TAG) encountered in other vegetable oils and animal fats $[1,2]$. The fatty acid component of jojoba wax esters primarily consists of eiconenoic, erucic, and oleic acids with cis-11-eicosen-1-ol and cis-13-docosen-1-ol principally composing the alcohol component [2]. Jojoba oil (JO) is currently used in cosmetics and hair care products, as well as a feedstock for lubricant and additive applications, as the viscosity index of JO is much higher than that of petroleum oil [3-6]. In addition, other uses of jojoba include diverse areas such as pharmaceutical, polishing, and gardening applications [7].

Biodiesel (BD), an alternative fuel composed of monoalkyl esters of long-chain FA prepared from renewable vegetable oils or animal fats [8], has attracted considerable interest as a substitute or blend component for conventional petroleum diesel fuel (petrodiesel). BD is prepared in the United States primarily from transesterification of soybean oil (SO) [9, 10]. Other feedstocks such as animal fats, used cooking oils, and canola oil may also be used where available. As a result of the high cost of $\mathrm{SO}$, other nonfood feedstocks for $\mathrm{BD}$ production have attracted considerable attention. The reaction conditions for the production of $\mathrm{BD}$ from $\mathrm{JO}$ have been studied using response surface methodology by Bouaid et al. [1]. In addition, selected physical properties of JME have been reported [2], along with indirect-injection (diesel) engine emissions characteristics [11].

The objective of the current study was to prepare JME from $\mathrm{JO}$, to measure important fuel properties such as kinematic viscosity, cloud point (CP), pour point (PP), cold filter plugging point (CFPP), cetane number $(\mathrm{CN})$, acid value (AV), oil stability (IP), and lubricity, and to compare these results with important $\mathrm{BD}$ standards such as the ASTM method D6751 [8] and the European Committee for Standardization method EN 14214 [12]. Furthermore, comparison of the properties of JME with SME was of interest. In order to reduce regulated exhaust emissions by $90 \%$, the Environmental Protection Agency (EPA) mandated the highway diesel rule in 2006. According to this rule, "sulfur content of highway diesel fuel should be reduced from 500 to 15 ppm." This reduced sulfur content diesel fuel is known as ultra-low sulfur diesel (ULSD, $\mathrm{S}<15 \mathrm{ppm}$ ) fuel [13]. Thus, lower sulfur diesel fuels reduce emissions of sulfur compounds (a cause of acid rain) and a major reason for reducing sulfur levels is to avoid poisoning of catalysts responsible for reducing these exhaust emissions species [14].

The impact of hydrodesulfurization on lubricity and lowtemperature properties of petrodiesel was significant due to reduced sulfur content as well as nitrogen, oxygen, olefinic content, and aromatic content of ULSD [15]. Therefore, to understand the effect of JME on lubricity and lowtemperature properties of ULSD, blends of JME in ULSD at 5 vol.\% (B5) and 20 vol.\% (B20) were prepared and evaluated for the above-mentioned properties and compared to the corresponding blends of SME in ULSD and relevant petrodiesel standards such as ASTM D975 [16] and D7467 [17].

\section{Materials and Methods}

\section{Materials}

PNJ Golden JO without commercial additives was purchased from Purcell Jojoba International (Lake Havasu City, AZ, USA) and used after acid-catalyzed pretreatment (APT). Refined, bleached, and deodorized (RBD) SO without commercial additives was purchased from KIC Chemicals (New Platz, NY, USA) and used as received. ULSD was donated by a major petrochemical company. Conductivity and corrosion inhibitor additives were added by the manufacturer to the ULSD, but no drag-reducing, lubricity, lowtemperature, or antioxidant additives were present. Phytosterol standards, stigmasterol, and $5 \alpha$-cholestane were purchased from Matreya (Pleasant Gap, PA, USA). Campesterol was purchased from Steraloids (Newport, RI, USA). $\beta$-Sitosterol and sitostanol were from Sigma-Aldrich (St. Louis, MO, USA). Each phytosterol standard has $\geq 97 \%$ purity. $N, O$-bis (trimethylsilyl)fluoroacetamide with $1 \%$ trimethylchlorosilane (BSTFA $+1 \%$ TMCS) was purchased from Regis (Morton Grove, IL, USA). All other chemicals and reagents were obtained from Aldrich Chemical Company (Milwaukee, WI, USA) and used as received.

\section{Infrared Spectroscopy}

Fourier transform infrared spectroscopy (FTIR) spectra were recorded on a Thermo Nicolet Nexus 470 FTIR system (Madison, WI, USA) with a Smart ARK accessory containing a $45 \mathrm{ZeSe}$ trough in a scanning range of 650 $4,000 \mathrm{~cm}^{-1}$ for 32 scans at a spectral resolution of $4 \mathrm{~cm}^{-1}$. 
Nuclear Magnetic Resonance Spectroscopy

${ }^{1} \mathrm{H}$ and ${ }^{13} \mathrm{C}$ nuclear magnetic resonance (NMR) spectra were recorded using a Bruker AV-500 spectrometer (Rheinstetten, Germany) operating at frequencies of 500.13 and $125.77 \mathrm{MHz}$, respectively, using a $5-\mathrm{mm}$ broadband inverse $\mathrm{Z}$-gradient probe in $\mathrm{CDCl}_{3}$ (Cambridge Isotope Laboratories, Andover, MA, USA) as solvent. Each spectrum was Fourier-transformed, phase-corrected, and integrated using the MestRe-C 2.3a (Magnetic Resonance Companion, Santiago de Compostela, Spain) software.

\section{Acid-Catalyzed Pretreatment of Jojoba Oil}

BD prepared with oil having higher AV (i.e., presence of free fatty acid) and base catalyst lead to soap formations and, consequently, increase in the formation of emulsions; this impacts on the yield of BD. Moreover, such BD also influence on certain physical properties of fuel. In order to overcome the above-mentioned short-falls, acid-catalyzed pretreatment of jojoba oil (APT-JO) was carried out as discussed below.

APT-JO was accomplished in a $1,000-\mathrm{mL}$ three-necked round-bottom flask connected to a reflux condenser and a mechanical magnetic stirrer set to $1,200 \mathrm{rpm}$. Initially, JO (431 g, $500 \mathrm{~mL}, 0.732 \mathrm{~mol})$ and methanol $(175 \mathrm{~mL}, 5.47 \mathrm{~mol})$ were added to the flask, followed by drop-wise addition of sulfuric acid (concentrated, $5 \mathrm{~mL}, 0.05 \mathrm{~mol}$ ). The contents were then heated at reflux for $2 \mathrm{~h}$. Upon cooling to room temperature (RT), the alcoholic phase was removed by gravity separation utilizing a separatory funnel. To remove residual methanol, the oil phase was washed with $5 \%$ sodium bicarbonate solution (three times) and distilled water $(3 \times$ $100 \mathrm{~mL}$ ), followed by rotary evaporation under reduced pressure. Finally, treatment with magnesium sulfate $\left(\mathrm{MgSO}_{4}\right)$ yielded dried and pretreated JO (427.4 g, 99.2 wt.\%).

\section{Transesterification of APT-JO}

Transesterification of APT-JO with methanol (Fig. 1) was accomplished following the procedure elucidated by Canoria et al. [2]. Freshly cut sodium metal $(0.736 \mathrm{~g}$, $0.032 \mathrm{~mol})$ was added to the methyl alcohol $(39.5 \mathrm{~g}$, $1.23 \mathrm{~mol}$ ) and allowed to dissolve for $30 \mathrm{~min}$. The methoxide solution was then poured over a mixture of JO $(172.4 \mathrm{~g}, 0.293 \mathrm{~mol})$ and methyl alcohol $(78.7 \mathrm{~g}, 2.46 \mathrm{~mol})$ and the mixture was heated at $65^{\circ} \mathrm{C}$ for $4 \mathrm{~h}$ with stirring (600 rpm) at reflux. Upon cooling to RT, the reaction mixture was neutralized with a drop-wise addition of concentrated $\mathrm{HCl}(2.8 \mathrm{~mL}, 0.032 \mathrm{~mol})$ while stirring. The excess alcohol was removed in vacuo by rotary evaporation and the crude mixture was dried with sodium sulfate and filtered to yield a mixture of jojoba oil methyl ester (JME) and jojobyl alcohol (JA).

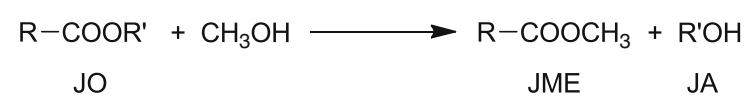

$\mathrm{R}=\mathrm{CH}_{3}\left(\mathrm{CH}_{2}\right)_{7}-\mathrm{CH}=\mathrm{CH}-\left(\mathrm{CH}_{2}\right)_{x^{-}}, \quad$ where $\mathrm{x}=7,9,11,13$
$\mathrm{R}^{\prime}=\mathrm{CH}_{3}\left(\mathrm{CH}_{2}\right)_{7}-\mathrm{CH}=\mathrm{CH}-\left(\mathrm{CH}_{2}\right)_{y^{-}}, \quad$ where $\mathrm{y}=8,10,12,14$
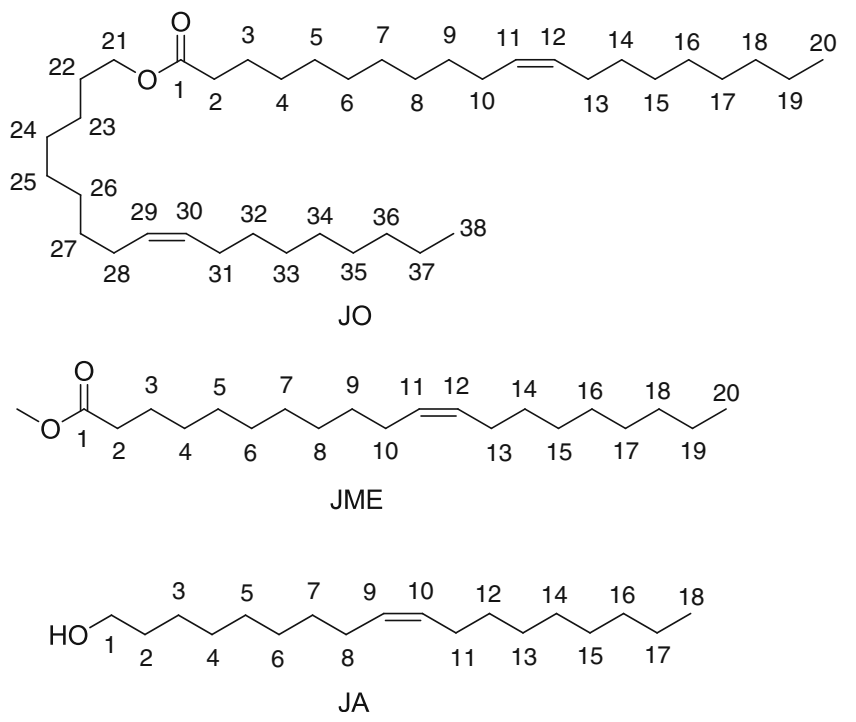

Fig. 1 Transesterification of jojoba oil (APT-JO) with methanol to yield JME and JA

\section{Purification of Jojoba Oil Methyl Ester}

The procedure used for the purification of JME was an adaptation of the method documented by Canoria et al. [2]. The mixture of JME and JA (43 g combined, $50 \mathrm{~mL}$ ) was dissolved in petroleum ether $(100 \mathrm{~mL}$; boiling point $=30$ $\left.60^{\circ} \mathrm{C}\right)$ and the solution was allowed to sit overnight $(16 \mathrm{~h})$ at approximately $-15^{\circ} \mathrm{C}$ in a freezer. The solid JA was rapidly removed by a simple vacuum filtration apparatus. This procedure was repeated until no precipitate was noticed in the sample after $16 \mathrm{~h}$ at $-15^{\circ} \mathrm{C}$. The petroleum ether was then removed by rotary evaporation to afford purified JME.

\section{Transesterification of Soybean Oil}

Methanolysis of SO was accomplished following the procedure set forth by Freedman et al. [18] and Moser [19] with sodium methoxide catalyst $(0.5 \mathrm{wt} . \%$ with respect to TAG), $6: 1$ mole ratio of methanol to TAG, $60^{\circ} \mathrm{C}$ internal reaction temperature, and $1.5 \mathrm{~h}$ reaction time. After sequential removal of glycerol by gravity separation and methanol by rotary evaporation, the crude methyl esters were washed with distilled water until a neutral $\mathrm{pH}$ was obtained. The ester phase was then dried by washing once with brine solution, followed by treatment with $\mathrm{MgSO}_{4}$ to 
yield purified and dried soybean oil methyl esters (SME) in essentially quantitative yield.

\section{Fatty Ester Profile by GC}

Fatty acid methyl esters (FAME) were separated using a Varian (Walnut Creek, CA, USA) 8400 gas chromatograph (GC) equipped with an flame ionization detector (FID) detector and SP2380 (Supelco, Bellefonte, PA, USA) column $(30 \mathrm{~m} \times 0.25 \mathrm{~mm}$ i.d., $0.20 \mu \mathrm{m}$ film thickness). Carrier gas was $\mathrm{He}$ at $1 \mathrm{~mL} / \mathrm{min}$. The oven temperature was held at $150^{\circ} \mathrm{C}$ for $15 \mathrm{~min}$, increased to $210^{\circ} \mathrm{C}$ at $2^{\circ} \mathrm{C} / \mathrm{min}$, followed by an increase to $220^{\circ} \mathrm{C}$ at $50^{\circ} \mathrm{C} / \mathrm{min}$. The injector and detector temperatures were $240^{\circ} \mathrm{C}$ and $270^{\circ} \mathrm{C}$, respectively. FAME peaks were identified by comparison to the retention times of known reference standards. Each FAME determination was run in triplicate and average values are reported.

\section{Phytosterol Content by GC}

Oils samples were saponified and phytosterols were extracted essentially as described by Dutta et al. [20, 21]. Phytosterols were manually injected onto a Varian 3400 GC equipped with an FID and a Supelco (Bellefonte, PA, USA) SPB ${ }^{\text {TM}}-1701(30 \mathrm{~m} \times 0.25 \mathrm{~mm} \times 0.25 \mu \mathrm{m})$ capillary column. Helium was used as a carrier gas, with a 1:50 injector split. Injector temperature was $270^{\circ} \mathrm{C}$, and detector temperature was $290^{\circ} \mathrm{C}$. The column oven initial temperature was $250^{\circ} \mathrm{C}$ for $0.5 \mathrm{~min}$, increased at $10^{\circ} \mathrm{C} / \mathrm{min}$ to $270^{\circ} \mathrm{C}$ and held for $27 \mathrm{~min}$, then increased at $10^{\circ} \mathrm{C} / \mathrm{min}$ to $280^{\circ} \mathrm{C}$ and held for $3.5 \mathrm{~min}$. Data collection and integration were performed using Varian Star Chromatography Software Version 5.3. Phytosterols were identified by comparison of their retention times (relative to the internal standard, $5 \alpha$ cholestane) with those of commercially available standards. Phytosterols without commercially available standards, such as $\Delta 5$-avenasterol, were identified by their relative retention time compared to literature $[20,21]$ and by comparison with samples known to contain those phytosterols. Quantitation was carried out by the internal standard method developed with available standards. For phytosterols with no available commercial standard, the response factor for $\beta$-sitosterol was used for quantitation.

\section{Low-Temperature Properties}

$\mathrm{CP}$ (in degrees Celsius) and PP (in degrees Celsius) determinations were made in agreement with ASTM D5773 [22] and ASTM D5949 [23], respectively, using a Phase Technology Analyzer model PSA-70S (Richmond, $\mathrm{BC}$, Canada). CP and PP are rounded to the nearest whole degree (in degrees Celsius). For a greater degree of accuracy, PP measurements were done with a resolution of $1{ }^{\circ} \mathrm{C}$ instead of the specified $3^{\circ} \mathrm{C}$ increment. CFPP (in degrees Celsius) was determined in accordance with ASTM D6371 [24] utilizing an ISL Automatic CFPP Analyzer model FPP 5Gs (Houston, TX, USA). Each sample was run in triplicate and mean values are reported.

\section{Kinematic Viscosity}

Kinematic viscosity ( $v$, in square millimeters per second) was determined with Cannon-Fenske viscometers CT-1000 (Cannon Instrument, State College, PA, USA) at $40^{\circ} \mathrm{C}$ in accordance with ASTM D445 [25]. All experiments were run in triplicate and mean values are reported.

\section{Lubricity}

Lubricity data (lub, in micrometers) was collected at $60^{\circ} \mathrm{C}$ (controlled to less than $\pm 1^{\circ} \mathrm{C}$ ), according to ASTM D6079 [26] using a high-frequency reciprocating rig lubricity tester (PCS Instruments, London, England) via Lazar Scientific (Granger, IN, USA). Wear scars (in micrometers) are the average of two replicates, measuring the maximum value of the $x$-axis and $y$-axis of the wear scar. The average wear scar diameter was determined by calculating the average of the $x$-axis and $y$-axis wear scar lengths.

\section{Acid Value}

$\mathrm{AV}$ is a measure of free fatty acids (FFA) present in BD. AV (in milligrams of $\mathrm{KOH}$ per gram) titrations were performed as described in the American Oil Chemists' Society (AOCS) official method Cd 3d-63 [27] using a Metrohm 836 Titrando (Westbury, NY, USA) autotitrator equipped with a model 801 stirrer, a Metrohm 6.0229.100 Solvotrode, and Tiamo 1.1 Light software. However, the standard method was modified for scale to use a larger scale of sample $(2 \mathrm{~g})$ and reagent $(0.02 \mathrm{M} \mathrm{KOH})$. The titration endpoint was determined by the instrument and visually verified using a phenolphthalein indicator. Each sample was run in triplicate and mean values are reported.

Iodine Value

The iodine value (IV) is a measure of the number of double bonds in the mixture of fatty acid chains in the BD. IV (in grams of $\mathrm{I}_{2}$ per $100 \mathrm{~g}$ ) was calculated from the fatty acid profile according to the AOCS official method Cd 1c-85 [28].

\section{Oxidative Stability}

Induction period (IP, in hours) was measured in accordance with EN 14112 [29] utilizing a Metrohm USA (Riverview, FL, USA) model 743 Rancimat instrument. For BD (B100) 
samples, the flow rate of air through $3 \pm 0.01 \mathrm{~g}$ of sample was $10 \mathrm{~L} / \mathrm{h}$ and the block temperature was set to $110^{\circ} \mathrm{C}$ with a correction factor $(\Delta T)$ of $1.5^{\circ} \mathrm{C}$. The glass conductivitymeasuring vessel contained $50 \pm 0.1 \mathrm{~mL}$ of distilled water. For BD samples blended with ULSD (B5 and B20), the flow rate of air through $7.5 \pm 0.1 \mathrm{~g}$ of sample was $10 \mathrm{~L} / \mathrm{h}$ with a block temperature of $110^{\circ} \mathrm{C}\left(\Delta T=1.5^{\circ} \mathrm{C}\right)$. The glass conductivity-measuring vessel contained $60 \pm 0.1 \mathrm{~mL}$ of distilled water. Longer reaction vessels and gas inlet tubes that were provided by the manufacturer were used in the case of the blends to keep the ULSD from evaporating from the sample tube in the heating block during experimentation. Each sample was run in triplicate and mean values are reported. The IP was mathematically determined as the inflection point of a computer-generated plot of conductivity (in microsiemens per centimeter) of distilled water versus time (in hours). Experiments were terminated at $24 \mathrm{~h}$.

Pressurized differential scanning calorimetry (PDSC) experiments were carried out using a PC-controlled DSC Q10 thermal analyzer from TA Instruments (New Castle, USA). The instrument has a maximum sensitivity of $5 \mathrm{mV}$ $\mathrm{cm}^{-1}$ and temperature sensitivity of $0.2 \mathrm{mV} \mathrm{cm}^{-1}$. A 1.5 - to 2.0-mg sample was placed in a hermetically sealed type aluminum pan with a pinhole lid for interaction of the sample with the reactant gas (dry air). The controlled diffusion of the gas through the hole greatly restricts the volatilization of the oil while still allowing for saturation of the liquid phase with air. A film thickness of less than $1 \mathrm{~mm}$ was required to ensure proper oil-air interaction and to eliminate any discrepancy in the result due to gas diffusion limitations. The module was first temperature calibrated using the melting point of indium metal $\left(156.6^{\circ} \mathrm{C}\right)$ at $10^{\circ} \mathrm{C} / \mathrm{min}$ heating rate. Dry air was pressurized in the module at a constant pressure of $1,378.95 \mathrm{kPa}(200 \mathrm{psi})$ and a scanning rate of $10^{\circ} \mathrm{C} / \mathrm{min}$ was used throughout the experiment. The onset temperature (OT, in degrees Celsius) and signal maximum temperature (SMT, in degrees Celsius) of oxidation were calculated from the exotherm in each case.

\section{Derived Cetane Number}

Derived cetane number $(\mathrm{CN})$ was determined by the Southwest Research Institute (San Antonio, TX, USA) utilizing an Ignition Quality Tester ${ }^{\mathrm{TM}}$ (IQT) in accordance to the ASTM standard D6890.32

\section{Results and Discussion}

\section{Preparation of Jojoba Oil Methyl Esters}

JME prepared by transesterification of JO (wax ester) with methanol (as shown in Fig. 1) was characterized by FTIR and NMR as shown in Table 1. As mentioned in the experimental section, at the conclusion of this preparation, a mixture of JME and JA was obtained. JME was separated from JA by an enhanced filtration method previously described [2] until no JA precipitate was noticed in a solution of JME in petroleum ether. However, the ${ }^{1} \mathrm{H}-\mathrm{NMR}$ spectrum of JME showed additional signals indicative of $\mathrm{JA}$ and $\mathrm{JO}$ at $\delta 3.63$ and $4.00 \mathrm{ppm}$, respectively, at very low concentrations. By comparing the spectra of JME and JA, it

Table 1 NMR and FTIR data for JO, JA, JME and SME

\begin{tabular}{|c|c|c|c|}
\hline Oil/methyl ester & FTIR (neat; $\mathrm{cm}^{-1}$ ) & ${ }^{1} \mathrm{H} \mathrm{NMR}\left(500 \mathrm{MHz}, \mathrm{CDCl}_{3}\right)$ & ${ }^{13} \mathrm{C}$ NMR $\left(125 \mathrm{MHz}, \mathrm{CDCl}_{3}\right)$ \\
\hline $\mathrm{JO}$ & $\begin{array}{l}3,004,2,921,2,852 \\
1,738,1,464,1,169 \\
721\end{array}$ & $\begin{array}{l}\delta 5.35(\mathrm{t}, 4 \mathrm{H}, \mathrm{C}-11,12,29,30), 4.06(\mathrm{t}, 2 \mathrm{H}, \\
\mathrm{C}-21), 2.29(\mathrm{t}, 2 \mathrm{H}, \mathrm{C}-2), 2.03(\mathrm{q}, 8 \mathrm{H}, \\
\mathrm{C}-1013,28,31), 1.62(\mathrm{t}, 2 \mathrm{H}, \mathrm{C}-3,22), 1.3 \\
\text { (brs, 33H, C 4,5,6,7,8,9,14,15,16,17,18, } \\
\text { 19,23, 24, 25,26,27,32,33,34,35,36,37), } \\
0.86(\mathrm{t}, 6 \mathrm{H}, \mathrm{C}-20,38)\end{array}$ & $\begin{array}{c}\delta 173.91(\mathrm{C}-1), 129.90-129.85(\mathrm{C}-10-\mathrm{C} 11, \\
\text { C29-C30), 64.36 (C-21), } 34.39(\mathrm{C}-2), 31.91 \\
(\mathrm{C}-18, \mathrm{C} 36), 29.77-29.17(\mathrm{C}-4,5,6,7,8,9,14, \\
15,16,17,24,25,26,27,28,32,33,34,35), 28.67 \\
(28,31), 27.21(\mathrm{C}-10,13), 25.95(\mathrm{C} 23), 25.02 \\
\text { (C-3), 22.68 (C-19,C37), } 14.08 \text { (C-20,C38) }\end{array}$ \\
\hline JA & $\begin{array}{l}3,332,3,004,2,920 \\
2,852,1,744,1,464 \\
1,171,1,056,721\end{array}$ & $\begin{array}{l}\delta 5.35(\mathrm{~m}, 2 \mathrm{H}, \mathrm{C}-10,11), 3.63(\mathrm{~s}, 2 \mathrm{H} \\
\mathrm{C}-2), 2.02(\mathrm{q}, 4 \mathrm{H}, \mathrm{C}-9,12), 1.56(\mathrm{t}, 2 \mathrm{H} \\
\mathrm{C}-3), 1.27 \text { (brs, } 11 \mathrm{H}, \mathrm{C}-4,5,6,7,8,13 \\
14,15,16,17,18), 0.86(\mathrm{t}, 3 \mathrm{H}, \mathrm{C}-19)\end{array}$ & $\begin{array}{l}\delta 129.9(\mathrm{C}-11), 129.8(\mathrm{C}-10), 63.0(\mathrm{C}-2), 32.8 \\
(\mathrm{C}-3), 31.9(\mathrm{C}-17), 29.8-29.3(\mathrm{C}- \\
5,6,7,8,13,14,15,16), 27.2(\mathrm{C}-9,12), 24.9 \\
(\mathrm{C}-3), 25.8(\mathrm{C}-4), 22.7(\mathrm{C}-18), 14.0(\mathrm{C}-19)\end{array}$ \\
\hline JME & $\begin{array}{l}3,004,2,922,2,852 \\
1,742,1,463,1,436 \\
1,170,721\end{array}$ & $\begin{array}{l}\delta 5.34(\mathrm{~m}, 2 \mathrm{H}, \mathrm{C}-11,12), 3.66(\mathrm{~s}, 3 \mathrm{H} \\
\mathrm{C}-21), 2.30(\mathrm{~m}, 2 \mathrm{H}, \mathrm{C}-2), 2.01(\mathrm{t}, 4 \mathrm{H} \\
\mathrm{C}-10,13), 1.62(\mathrm{~m}, 2 \mathrm{H}, \mathrm{C}-3), 1.30 \\
(\mathrm{~m}, 24 \mathrm{H}, \mathrm{C}-4,5,6,7,8,9,14,15,16,17 \\
18,19), 0.86(\mathrm{t}, 3 \mathrm{H}, \mathrm{C}-20)\end{array}$ & $\begin{array}{l}\delta 174.5(\mathrm{C}-1), 129.86(\mathrm{C}-12), 129.82(\mathrm{C}-11) \\
51.34(\mathrm{C}-21), 34.07(\mathrm{C}-2), 31.9(\mathrm{C}-18) \\
29.76-29.11(\mathrm{C}-4,5,6,7,8,9,14,15,16,17) \\
27.19(\mathrm{C}-10,13), 24.94(\mathrm{C}-3), 22.6(\mathrm{C}-19) \\
14.06(\mathrm{C}-20)\end{array}$ \\
\hline SME & $\begin{array}{l}3,009,2,923,2,854 \\
1,741,1,459,1,435 \\
1,361,1,244,1,195 \\
1,170,1,121,1,016 \\
913,883,844,722\end{array}$ & $\begin{array}{l}\delta 5.36(\mathrm{~m}, 2 \mathrm{H}, \text { vinyl), } 3.67(\mathrm{~s}, 3 \mathrm{H}, \\
\left.-\mathrm{OCH}_{3}\right), 2.78(\mathrm{~m}, 2 \mathrm{H}, \text { bis-allylic) }, 2.31 \\
(\mathrm{t}, 2 \mathrm{H}, \text { allylic), } 2.05(\mathrm{~m}, 2 \mathrm{H}, \alpha \text { to ester), } \\
1.63(\mathrm{~m}, 2 \mathrm{H}, \beta \text { to ester }), 1.29(\mathrm{~m}, 28 \mathrm{H}, \\
\text { methylene }), 0.90(\mathrm{t}, 3 \mathrm{H}, \text { terminal methyl) }\end{array}$ & \\
\hline
\end{tabular}


was established that the proton signal at $\delta 3.63 \mathrm{ppm}$ was due to protons attached to $\mathrm{C} 2$ of $\mathrm{JA}$, while the signal at $\delta$ $4.00 \mathrm{ppm}$ was due to protons attached to C21 of JO. Therefore, the ratio of these signals to the methoxy protons of JME ( $\delta 3.66 \mathrm{ppm})$ was used to determine the purity of JME. The ratio of protons at $3.66,3.63$, and $4.06 \mathrm{ppm}$ was 1.00:0.045:0.0.036 (93:4:3). From this ratio, it was determined that JME was a mixture of $93 \% \mathrm{JME}, 4 \% \mathrm{JA}$, and $3 \%$ JO. Previous reports [2] obtained JME in $79 \%$ purity, indicating that our modification in JO pretreatment as well as the purification method resulted in higher-purity JME. SME was also prepared from SO (triglyceride) in high yield by homogenous, base-catalyzed transesterification with methanol (as shown in Fig. 2) following the literature procedure $[18,19]$. SME was characterized by FTIR and NMR as shown in Table 1.

\section{Fatty Acid Composition}

The fatty acid profiles of JME and SME oils are shown in Table 2. The main FA found in JO is gondoic acid (C20:1, $59.5 \%)$, with erucic $(\mathrm{C} 22: 1,12.3 \%)$, oleic $(\mathrm{C} 18: 1,10.7 \%)$, and arachidonic $(20: 4,9.1 \%)$ acids noticed in considerable amounts. Other minor FA found included docotetrasenoic (C22:4, 3.7\%), nervonic (C24:1, 1.7\%), and palmitic (C16:0, 1.2\%) acids. The average molecular weight (MW) of JME was $325.38 \mathrm{~g} / \mathrm{mol}$, which was calculated from the FA profile.

The main FA found in SME was linoleic acid (C18:2, $52.4 \%)$, with oleic $(\mathrm{C} 18: 1,22.1 \%)$ and palmitic (C16:0, $11.4 \%$ ) acids also noticed in considerable amounts. Other minor FA included linolenic (C18:3, 7.4\%), stearic (C18:0, $3.9 \%)$, and vaccenic $(\mathrm{C} 18: 1 \Delta 11,1.6 \%)$ acids. This result was in agreement with previous reports on the SME FA profile $[15,19]$. The average MW of SME was $292.46 \mathrm{~g} / \mathrm{mol}$, which was calculated from the FA profile.

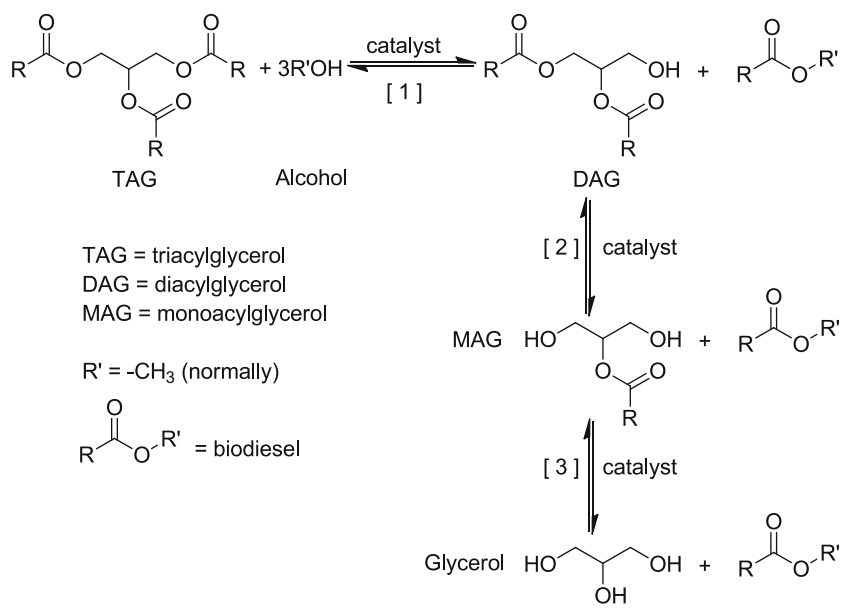

Fig. 2 Transesterification of TAG to yield fatty acid alkyl esters (BD)
Table 2 Fatty acid compositions (in weight percent) of JME and SME

\begin{tabular}{|c|c|c|c|}
\hline Fatty acid ${ }^{\mathrm{a}}$ & Name of fatty acid & JME & SME \\
\hline 14:0 & Myristic & 0 & 0.1 \\
\hline $16: 0$ & Palmitic & 1.2 & 11.4 \\
\hline $18: 0$ & Stearic & 0 & 3.9 \\
\hline $20: 0$ & Arachidic & 0 & 0.2 \\
\hline $22: 0$ & Behenic & 0.2 & 0.3 \\
\hline $16: 1 \Delta 9$ & Palmitoleic & 0 & 0.1 \\
\hline $18: 1 \Delta 9$ & Oleic & 10.7 & 22.1 \\
\hline $18: 1 \Delta 11$ & Vaccenic & 0.3 & 1.6 \\
\hline $20: 1 \Delta 11$ & Gondoic & 59.5 & 0.2 \\
\hline $22: 1 \Delta 13$ & Erucic & 12.3 & 0.0 \\
\hline $24: 1 \Delta 15$ & Nervonic & 1.7 & 0.0 \\
\hline $18: 2 \Delta 9,12$ & Linoleic & 0.1 & 52.4 \\
\hline $18: 3 \Delta 9,12,15$ & Linolenic & 0.4 & 7.4 \\
\hline $20: 4 \Delta 5,8,11,14$ & Arachidonic & 9.1 & 0 \\
\hline $22: 4 \Delta 7,10,13,16$ & Docotetrasenoic & 3.7 & 0 \\
\hline Unknown (sum) & & 0.8 & 0.3 \\
\hline$\sum \mathrm{sat}^{\mathrm{b}}$ & & 1.4 & 15.9 \\
\hline$\sum$ monounsat $^{\mathrm{c}}$ & & 84.5 & 24.0 \\
\hline$\sum$ polyunsat $^{\mathrm{d}}$ & & 13.3 & 59.8 \\
\hline
\end{tabular}

${ }^{\mathrm{a}}$ The first number indicates the length of the fatty acid chain and the second the number of double bonds (all cis) with $\Delta$ signifying the location of the double bond(s)

${ }^{\mathrm{b}} \sum \mathrm{sat}=14: 0+16: 0+18: 0+20: 0+22: 0$

${ }^{\mathrm{c}} \sum$ monounsat $=16: 1+18: 1+20: 1+22: 1+24: 1$

${ }^{\mathrm{d}} \sum$ polyunsat $=18: 2+18: 3+20: 4+22: 4$

Phytosterol Content

Table 3 shows the phytosterol content and composition of $\mathrm{JO}$ and SO. The primary phytosterol detected in JO was sitosterol $(2.62 \mathrm{mg} / \mathrm{g})$, which comprised $71 \%$ of the total phytosterol content. The phytosterol content of JO was in agreement with values reported by Van Boven et al. [30]; and the phytosterol content of $\mathrm{JO}$ is within the range of most vegetable oils. The principle phytosterol found in $\mathrm{SO}$ was also sitosterol $(2.09 \mathrm{mg} / \mathrm{g})$, which represents $49 \%$ of the total content of phytosterol [31].

\section{Low-Temperature Properties}

JME shows the best low-temperature properties, as indicated by $\mathrm{CP}$ and $\mathrm{PP}$ values of $-13^{\circ} \mathrm{C}$ and $-16^{\circ} \mathrm{C}$ versus $0^{\circ} \mathrm{C}$ and $-3^{\circ} \mathrm{C}$ for SME (Table 4). The same trend was observed for CFPP where JME showed a value of $-14^{\circ} \mathrm{C}$ versus $-4^{\circ} \mathrm{C}$ for SME. This may be due to the comparatively low saturated FA present in JME (1.4 wt.\%; Table 2) in comparison to SME (15.9 wt.\%; Table 2). The presence of more saturated FA esters deteriorates the low-temperature properties. This 
Table 3 Phytosterol (in milligrams per gram) content of JO and RBD SO

\begin{tabular}{lll}
\hline & JO & RBD SO \\
\hline Campesterol & $0.65(0.01)$ & $0.94(0.04)$ \\
Stigmasterol & $0.29(0.0)$ & $0.69(0.02)$ \\
Sitosterol & $2.62(0.03)$ & $2.09(0.07)$ \\
Sitostanol & 0 & $0.06(0.01)$ \\
Avenasterol & $0.15(0.0)$ & $0.15(0.01)$ \\
Cycloartenol & 0 & $0.24(0.01)$ \\
Citrostadienol & 0 & $0.13(0.01)$ \\
$\sum$ phyto & $3.71(0.04)$ & $4.29(0.11)$ \\
\hline
\end{tabular}

Values in parentheses are the standard deviation from the reported mean

$\sum$ phyto sum of all phytosterols

${ }^{\mathrm{a}}$ Data from reference [31]

observation is in agreement with previous work where a statistically significant relationship between saturated FA content and low-temperature operability was discussed [19].

The low-temperature properties of JME and SME blended at 5 and 20 vol. $\%$ with ULSD were measured (Table 5). Both the $5 \%$ and $20 \%$ blends of JME and SME in ULSD had negligible impact on the CP, PP, and CFPP of ULSD. This result demonstrates that both JME and SME can be blended with ULSD without any major impact on the ULSD low-temperature properties.

Interestingly, JO showed the opposite trend in lowtemperature properties (CP, PP, and CFPP) compared to SO. This reverse trend in oil may be due to long-chain fatty acid and fatty alcohol of JO.

\section{Lubricity}

It is known that fuels containing heteroatom such as $\mathrm{S}$ exhibit higher lubricities; however, removal of $\mathrm{S}$ compounds also removes compounds with $\mathrm{O}$ and $\mathrm{N}$ from petrodiesel, which are the actual lubricity-imparting species [32]. Fuels based on vegetable monoesters also show better lubricity compared to petrodiesel, as fatty compounds contain more polarity-imparting $\mathrm{O}$ atoms [32]. Prescher et al. [33] reported that fuels producing wear scars of $460 \mu \mathrm{m}$ or shorter at $60^{\circ} \mathrm{C}$ in a diesel engine are acceptable for practical use.

Lubricity data for JME and SME is displayed in Table 4. Both JME and SME showed wear scars $<165 \mu \mathrm{m}$ and their B5 and B20 blends in ULSD showed wear scars $<320 \mu \mathrm{m}$ (Tables $4 \& 5$ ). These results are far better than ASTM D975 as well as EN 590 standards requirement which are 520 and $460 \mu \mathrm{m}$ maximum, respectively. Based on previous studies [15], it was expected that both blends should show

Table 4 Physical properties of JO and SO, and JME and SME

\begin{tabular}{|c|c|c|c|c|c|c|c|}
\hline Property & ASTM D6751 & EN 142124 & $\mathrm{JO}$ & APT-JO & JME APT & SO RBD & SME \\
\hline $\mathrm{CP},{ }^{\circ} \mathrm{C}$ & Report & - & $8(1)$ & $7(1)$ & $-13(1)$ & $-7(1)$ & $0(1)$ \\
\hline $\mathrm{PP},{ }^{\circ} \mathrm{C}$ & - & - & $5(1)$ & $4(1)$ & $-16(1)$ & $-9(1)$ & $-3(1)$ \\
\hline $\mathrm{CFPP},{ }^{\circ} \mathrm{C}$ & - & Depends $^{\mathrm{a}}$ & $20(1)$ & $20(1)$ & $-14(1)$ & $\mathrm{b}$ & $-4(1)$ \\
\hline Lub, $\mu \mathrm{m}$ & - & - & $151(9)$ & $217(3)$ & $165(6)$ & $124(2)$ & $135(5)$ \\
\hline$v, \mathrm{~mm}^{2} / \mathrm{s}$ & $1.9-6.0$ & $3.5-5.0$ & $25.00(0.01)$ & $21.06(0.03)$ & $6.67(0.02)$ & $31.49(0.03)$ & $4.12(0.01)$ \\
\hline $\mathrm{IP}, \mathrm{h}$ & $3.0 \mathrm{~min}$ & $6.0 \mathrm{~min}$ & $60(3)$ & $34(1)$ & $0.35(0.03)$ & $8.3(0.2)$ & $5.0(0.1)$ \\
\hline AV & $0.50 \max$ & $0.50 \max$ & $0.68(0.1)$ & $0.06(0.02)$ & $1.37(0.02)$ & $0.03(0.03)$ & $0.01(0.01)$ \\
\hline $\mathrm{OT},{ }^{\circ} \mathrm{C}$ & - & - & $188(0.2)$ & $184(0.5)$ & $176(0.7)$ & $180(0.5)$ & $179(0.8)$ \\
\hline $\mathrm{SMT},{ }^{\circ} \mathrm{C}$ & - & - & $208(0.2)$ & $206(0.4)$ & $202(0.3)$ & $196(0.2)$ & $193(0.5)$ \\
\hline $\mathrm{CN}$ & $47 \mathrm{~min}$ & $51 \mathrm{~min}$ & - & 74 & 69 & - & $54^{\mathrm{c}}$ \\
\hline IV & - & $120 \max$ & d & d & 108 & 130 & 130 \\
\hline
\end{tabular}

Values in parenthesis are standard deviations from the reported means ( $n=3$ and $n=2$ in the case of lubricity)

$J O$ jojoba oil, $A P T-J O$ jojoba oil after pretreatment, $A P T-J M E$ jojoba oil methyl esters after pretreatment, $R B D S O$ refined, bleached, and deodorized soybean oil, $S M E$ soybean oil methyl esters, $C P$ cloud point, $P P$ pour point, $C F P P$ cold filter plugging point, $L u b$ lubricity $\left(60^{\circ} \mathrm{C}\right), v$ kinematic viscosity $\left(40^{\circ} \mathrm{C}\right), I P$ oil stability index $\left(110^{\circ} \mathrm{C}\right), A V$ acid value, $O T$ oxidation onset temperature, $S M T$ signal maximum temperature, $C N$ cetane number, $I V$ iodine value

${ }^{\text {a }}$ Varies according to location and time of year

${ }^{\mathrm{b}}$ Test not conducted due to the high viscosity of RBD SO

${ }^{\mathrm{c}}$ Please see reference no. [42]

${ }^{\mathrm{d}}$ Due to the wax ester nature of JO, IV was not calculated 
Table 5 Physical properties of JME and SME blended at 5 and 20 vol.\% with ULSD

\begin{tabular}{|c|c|c|c|c|c|c|c|}
\hline Property & ASTM D975 & ASTM D7467 & ULSD & JME APT B5 & SME B5 & JME APT B20 & SME B20 \\
\hline BD, vol. $\%$ & $0-5$ & $6-20$ & 0 & 5 & 5 & 20 & 20 \\
\hline $\mathrm{CP},{ }^{\circ} \mathrm{C}$ & Report & - & $-18(1)$ & $-15(1)$ & $-16(1)$ & $-16(1)$ & $-12(1)$ \\
\hline $\mathrm{PP},{ }^{\circ} \mathrm{C}$ & - & - & $-23(0)$ & $-25(1)$ & $-22(1)$ & $-21(0)$ & $-17(1)$ \\
\hline CFPP, ${ }^{\circ} \mathrm{C}$ & - & - & $-16(1)$ & $-16(0)$ & $-17(1)$ & $-16(0)$ & $-16(1)$ \\
\hline Lub, $\mu \mathrm{m}$ & $520 \max$ & $520 \max$ & 493 (14) & $320(7)$ & $198(4)$ & $222(8)$ & $143(4)$ \\
\hline$v, \mathrm{~mm}^{2} / \mathrm{s}$ & $1.9-4.1$ & $1.8-4.1$ & $2.34(0.01)$ & $2.45(0.01)$ & $2.37(0.01)$ & $2.96(0.01)$ & $2.54(0.01)$ \\
\hline IP, h & - & $6.0 \mathrm{~min}$ & $>24$ & $21.1(6.0)$ & $>24$ & $17(2)$ & $17.1(0.2)$ \\
\hline $\mathrm{AV}$ & - & $0.3 \max$ & $0.02(0.02)$ & $0.02(0.02)$ & $0.01(0.01)$ & $0.16(0.01)$ & $0.01(0.01)$ \\
\hline $\mathrm{OT},{ }^{\circ} \mathrm{C}$ & - & - & $198(0.4)$ & $194(0.2)$ & $198(0.4)$ & $188(0.2)$ & $196(0.1)$ \\
\hline $\mathrm{SMT},{ }^{\circ} \mathrm{C}$ & - & - & $213(0.5)$ & $211(0.5)$ & $210(0.9)$ & $208(0.9)$ & $207(0.4)$ \\
\hline
\end{tabular}

Values in parenthesis are standard deviations from the reported means ( $n=3$ and $n=2$ in the case of lubricity)

$C P$ cloud point, $P P$ pour point, $C F P P$ cold filter plugging point, $L u b$ lubricity $\left(60^{\circ} \mathrm{C}\right), v$ kinematic viscosity $\left(40^{\circ} \mathrm{C}\right), I P$ oil stability index $\left(110^{\circ} \mathrm{C}\right)$, $A V$ acid value, $O T$ oxidation onset temperature, $S M T$ signal maximum temperature

better lubricity than that of neat ULSD. Lubricity data shown in Table 4 are consistent with this expectation.

\section{Kinematic Viscosity}

The reason why vegetable oil by itself has been largely abandoned for use as BD fuel is due to kinematic viscosity [34]. JO and SO kinematic viscosities are nearly the same (Table 4). However, SME shows lower viscosity compared to JME by $\sim 2 \mathrm{~mm}^{2} \mathrm{~s}^{-1}$ at $40^{\circ} \mathrm{C}$. As previously mentioned, the higher polyunsaturated FAME content of SME versus JME may in part explain this result, as it is known that polyunsaturation lowers kinematic viscosity [35]. In addition, the presence of long-chain fatty alcohols and residual JO in JME may also contribute to the higher kinematic viscosity of JME. The kinematic viscosities of the B5 and B20 blends of JME as well as SME in ULSD are shown in Table 5. Both blend series satisfied the ASTM D975 and D7467 standards, with JME blends exhibiting slightly elevated viscosities in comparison to SME blends.

\section{Iodine Value}

SME showed higher IV than that of JME. This may be due to the higher polyunsaturated content of SME (Table 2). The IV of SME (130) was higher than the maximum limit specified in EN $14214(<120)$, whereas JME was below this limit (108). The American BD standard, ASTM D6751, does not specify limits for IV.

\section{Oxidative Stability}

JO showed the highest IP of $60 \mathrm{~h}$, while SO showed only $5 \mathrm{~h}$ (Table 4). The higher IP of JO is attributed to the resonance effect along the linear chain of 38 to 44 carbons.
The double bonds are widely separated and are more or less equidistant from the central ester linkage. These bonds are considered inaccessible and their shared electrons are well protected against oxidation. However, in the case of vegetable oils such as SO, typically having $60 \%$ polyunsaturated FA, the double bonds are in close proximity. Due to this close proximity, these double bonds are highly susceptible towards oxidation $[36,37]$. JME showed lower IP compared to SME (Table 4). This might be due to the lower amount of saturated FAME in JME compared to SME as well as the decrease in the long chain of JO to half in the case of JME, thus making the double bond more accessible for oxidation. Neither SME nor JME were acceptable according to the limit specified in EN 14214 with regard to IPI $(>6.0 \mathrm{~h})$. However, SME was satisfactory when compared to ASTM D6751 ( $>3.0 \mathrm{~h})$, but JME was not. These results indicate that both JME and SME would require antioxidants. The oxidative stability of ULSD decreased as the percentage of $\mathrm{BD}$ was increased from 0 to 20 vol.\% (Table 5). This decrease was more pronounced in the case of JME blends. However, the oxidative stabilities of the B20 blends were satisfactory according to ASTM D7467 ( $>6.0$ h). ASTM D975 (up to B5) does not contain oxidative stability limits.

Acid Value

The AV of JO as well as JME was higher than that of SO and SME (Table 4). As SO was refined, bleached, and deodorized, most of the FFA had been removed. This is reflected in the $\mathrm{AV}$ of $\mathrm{SO}$, which was 0.03 . In addition, SME had an AV of 0.01. In the case of JO, the AV before pretreatment was 0.68 and after pretreatment was 0.06 , while in the case of JME, it was 1.37 , which might be responsible for the reduced product prepared from APT-JO 
(92 wt.\%) yields of JME. Although SME was satisfactory according to the AV limits contained within the ASTM D6751 $(<0.50)$ and EN $14214(<0.50)$, JME was not. Correspondingly, blends of JME in ULSD showed higher AV than SME blends (Table 5). In fact, B20 JME and B20 SME showed an AV of 0.16 and 0.01 , correspondingly, which were within the limit of the ASTM D7467 $(<0.30)$. ASTM D975 does not contain limits on AV.

\section{Pressurized Differential Scanning Calorimetry}

PDSC has been shown to be an effective tool in the measurement of oxidative stability in oleochemicals and lubricants [38-41]. The OT is the temperature at which a rapid increase in the rate of oxidation is observed and obtained by extrapolating the tangent drawn on the steepest slope of reaction exotherm to the baseline. A high OT would suggest a high oxidation stability of the oil. PDSC data for neat JO, APT-JO, SO, JME, and SME are depicted in Table 4 and B5 and B20 blend data are depicted in Table 5.

It appears from the PDSC results that, after the removal of FFA, the oxidation stability of JO has gone down by $4^{\circ} \mathrm{C}$. This is also confirmed from the IP results of the same. Table 4 shows that the oxidation stability data (OT and SMT) for JO, APT-JO, JME, SO, and SME are in agreement with the IP data. Interestingly, there is no OT difference between SO and SME, while there is an $8^{\circ} \mathrm{C}$ difference between JO and JME. As discussed before in the "Oxidative Stability" section, this might be due to the decrease in the overall chain length of JME in comparison to JO, thus making the double bond more accessible for oxidation. The higher OT of SME compared to JME may be due to the higher amount of saturated FAME present in SME.

Table 5 shows the change in oxidation stability of ULSD on the addition of JME and SME. As there was a $22^{\circ} \mathrm{C}$ difference in OT of ULSD and JME, the decrease in OT of ULSD blends with the addition of JME was obvious. The ULSD showed an OT of $198^{\circ} \mathrm{C}$, while B20 JME showed an OT of $188^{\circ} \mathrm{C}$. As in the case of IP, the addition of BD to ULSD resulted in a reduction in OT of ULSD, which was more pronounced for JME blends.

\section{Conclusions}

The following conclusions were elucidated from the results discussed above and are summarized below:

1. Neat JME showed better low-temperature properties than that of SME. Blends (B5 and B20) of JME with ULSD showed better or equal low-temperature properties than that of the corresponding SME blends.
2. The lubricity of neat JME was similar to that of neat SME. Blends (B5 and B20) of SME with ULSD showed similar or better lubricities than the corresponding JME blends. All blends satisfied the ASTM D7467 and D975 lubricity specifications.

3. The kinematic viscosity of neat SME was within the ASTM D6571 specification whereas neat JME was not. However, all blends were within specifications contained within the ASTM D975 and D7467.

4. The IV of SME was higher than that of JME as a result of the higher polyunsaturated FAME content of SME. The IV of JME was satisfactory according to EN 14214 whereas SME was not.

5. JME exhibited lower IP compared to SME. Addition of an antioxidant would be required to satisfy the oxidative stability requirements in ASTM D6751 and EN 14214. However, B20 blends of JME as well as SME were within the ASTM D7467 specification. The B5 blends were even more stable than the B20 blends.

6. The AV of neat SME was within the ASTM D6751 specification whereas neat JME did not satisfy this limit. However, both blends of SME and JME were satisfactory according to the limits in ASTM D7467. In addition, the B5 blends exhibited lower AV than the B20 blends.

7. IP studies of JME as well as SME were in agreement with results obtained from the PDSC study.

In conclusion, it was demonstrated that the B5 and B20 blends of JME in ULSD had acceptable fuel properties. In summary, JO has the potential as an alternative nonfood feedstock for BD production.

By the encouraging low-temperature property results discussed above, our future plan is to prepare more alkyl ester derivatives of JO to see the effect of alkyl chain length on the low-temperature properties as well as their influence on other fuel properties.

Acknowledgements The authors acknowledge Jill K. WinklerMoser for the acquisition of phytosterol data and Erin L. Walter for the excellent technical assistance.

\section{References}

1. Bouaid A, Bajo L, Martinez M, Aracil J (2007) Optimization of biodiesel production from jojoba oil. Process Saf Environ Protect 85:378-382

2. Canoira L, Alcantara R, Garcia-Martinez MJ, Carrasco J (2006) Biodiesel from jojoba oil-wax: transesterification with methanol and properties as a fuel. Biomass Bioenergy 30:76-81

3. Sivasankarn GA, Bisht RPS, Jain VK, Gupta M (1998) Jojoba oil based two stroke gasoline engine lubricant. Tribol Int 21:327-333

4. Bhatia VK, Chaudhary A, Masohan A, Sivasankarn GA, Bisht RPS (1988) Sulphurization of jojoba oil for application as additive. J Am Oil Chem Soc 65:1502-1507 
5. Bhatia VK, Chaudhary A, Sivasankarn GA, Bisht RPS, Kashyap M (1990) Modification of jojoba oil for lubricant formulation. J Am Oil Chem Soc 67:1-7

6. Bisht RPS, Sivasankarn GA, Bhatia VK (1993) Additive properties of jojoba oil for lubricating oil formulation. Wear 161:193-197

7. Shani A (1995) The struggles of jojoba. Chemtech 25(5):49-54

8. American Society for Testing and Materials (2008) Standard specification for biodiesel fuel (B100) blend stock for distillate fuels. In: Annual Book of ASTM Standards, ASTM International, West Conshohocken, PA, Method D6751

9. Gerpen JV, Knothe G (2008) Bioenergy and biofuels from soybeans. In: Johnson LA, White PJ, Galloway R (eds) Soybeans chemistry, production, processing and utilization. AOCS, Urbana, IL, USA, p 502

10. Knothe G, Gerpen JV, Krahl J (eds) (2005) The biodiesel handbook. AOCS, Urbana, IL, USA

11. Selim MYE, Radwan MS, Elfeky SMS (2003) Combustion of jojoba methyl ester in an indirect injection diesel engine. Renew Energy 28:1401-1420

12. Committee for Standardization (2003) Automotive fuels - fatty acid methyl esters (FAME) for diesel engines - requirements and test methods. European Committee for Standardization Press, Brussels, Method EN 14214:2003

13. Wadumesthrige K, Ara M, Salley SO, SimonNg KY (2009) Investigation of lubricity characteristics of biodiesel in petroleum and synthetic fuel. Energy Fuels 23:2229-2234

14. Tan PQ, Hu ZY, Lou DM (2009) Regulated and unregulated emissions from a light duty diesel engine with different sulfur content fuels. Fuel 88:1086-1091

15. Moser BR, Cermak SC, Isbell TA (2008) Evaluation of castor and lesquerella oil derivatives as additives in biodiesel and ultralow sulfur diesel fuel. Energy Fuels 22:1349-1352

16. American Society for Testing and Materials (2008) Standard specification for diesel fuel oils. In: Annual Book of ASTM Standards, ASTM International, West Conshohocken, PA, Method D975

17. American Society for Testing and Materials (2008) Standard specification for diesel fuel oil, biodiesel blend (B6 to B20). In: Annual Book of ASTM Standards, ASTM International, West Conshohocken, PA, Method D7467

18. Freedman B, Pryde EH, Mounts TL (1984) Variables affecting the yields of fatty esters from transesterified vegetable oils. J Am Oil Chem Soc 61:1638-1643

19. Moser BR (2008) Influence of blending canola, palm, soybean, and sunflower oil methyl esters on fuel properties of biodiesel. Energy Fuels 22:4301-4306

20. Dutta PC, Normén L (1998) Capillary column gas-liquid chromatographic separation of $\Delta 5$-unsaturated and saturated phytosterols. J Chrom A 816:177-184

21. Winkler JK, Rennick KA, Eller FJ, Vaughn SF (2007) Phytosterol and tocopherol components in extracts of corn distillers dried grain. J Agric Food Chem 55:6482-6486

22. American Society for Testing and Materials (2007) Standard test method for cloud point of petroleum products (constant cooling rate method). In: Annual Book of ASTM Standards, ASTM International, West Conshohocken, PA, Method D5773

23. American Society for Testing and Materials (2001) Standard test method for pour point of petroleum products (automatic pressure pulsing method). In: Annual Book of ASTM Standards, ASTM International, West Conshohocken, PA, Method D5949

24. American Society for Testing and Materials (2005) Standard test method for cold filter plugging point diesel and heating fuels. In: Annual Book of ASTM Standards, ASTM International, West Conshohocken, PA, Method D6371
25. American Society for Testing and Materials (2006) Standard test method for kinematic viscosity of transparent and opaque liquids (and calculation of dynamic viscosity). In: Annual Book of ASTM Standards, ASTM International, West Conshohocken, PA, Method D445

26. American Society for Testing and Materials (2004) Standard test method for evaluating lubricity of diesel fuels by high frequency reciprocating rig (HFRR). In: Annual Book of ASTM Standards, ASTM International, West Conshohocken, PA, Method D6079

27. American Oil Chemists Society (1999) Acid value. In: Official methods and recommended practices of the American Oil Chemists Society, 5th edn. AOCS, Champaign, pp Cd 3d-63

28. American Oil Chemists Society (1999) Calculated iodine value. In: Official methods and recommended practices of the American Oil Chemists Society, 5th edn. AOCS, Champaign, pp Cd 1c-85

29. Committee for Standardization (2003) Fat and oil derivatives. Fatty acid methyl esters (FAME). Determination of oxidative stability (accelerated oxidation test). European Committee for Standardization Press, Brussels, Method EN 14112:2003

30. Van Boven M, Daenens P, Maes K, Cokelaere M (1997) Content and composition of free sterols and free fatty alcohol in jojoba oil. J Agric Food Chem 45:1180-1184

31. Moser BR, Shah SN, Winkler-Moser JK, Vaughn SF, Evangelista RL (2009) Composition and physical properties of cress (Lepidium sativum L.) and field pennycress (Thlaspi arvense L.) oils. Ind Crop Prod 30(2):199-205. doi:10.1016/j.indcorp.2009.03.007

32. Knothe G, Steidley KR (2005) Lubricity of components of biodiesel and petro diesel. The origin of biodiesel lubricity. Energy Fuels 19(3):1192-1200

33. Prescher K, Wichman V (2001) Auswirkungen des zusatzes von rapsolmethylester (RME) auf die schmierfahigkeit von schwefelarmem dieselkraftstoff nach DIN EN (neu). Report University of Rostock, Germany, FKZ: 99NR048

34. Knothe G (2005) Dependence of biodiesel fuel properties on the structure of fatty acid alkyl esters. Fuel Process Technol 86:10591070

35. Knothe G, Steidley KR (2005) Kinematic viscosity of biodiesel fuel components and related compounds. Influence of compound structure and comparison to petrodiesel fuel components. Fuel 84:1059-1065

36. Wisniak J (1987) The chemistry and technology of jojoba oil. American Oil Chemists' Society, Champaign, pp 183-187

37. Cosmetic chemistry of natural jojoba. Jojoba extraordinary oxidative stability, p 11. Available at http://www.purcelljojoba. com/JojobaTechInfo/JojobaChemistryGuide/JojobaChemistry GuideEnglish.pdf

38. Dunn RO (2005) Effect of antioxidants on the oxidative stability of methyl soyate (biodiesel). Fuel Process Technol 86(10):10711085

39. Zhang YY, Ren TH, Wang HD, Yi MR (2004) A comparative study of phenol-type antioxidants in methyl oleate with quantum calculations and experiments. Lubr Sci 16:385-392

40. Adhvaryu A, Biresaw G, Sharma BK, Erhan SZ (2006) Friction behavior of some seed oils: biobased lubricant applications. Ind Eng Chem Res 45:3735-3740

41. Sharma BK, Stipanovic A (2003) Development of a new oxidation stability test method for lubricating oils using highpressure differential scanning calorimetry. Thermochim Acta 402 $(1-2): 1-18$

42. Knothe G, Sharp CA, Ryan TW III (2006) Exhaust emissions of biodiesel, petrodiesel, neat methyl esters and alkanes in a new technology. Energy Fuels 20:403-408 